\title{
Mariano Picón-Salas
}

\section{INTUICION DE CHILE}

CUAL es el destino de esta tierra larga y estrecha que guarda en la angosta y rugosa cinta de su Geografía, la suma dulzura de un valle Central, cuajado de frutas y el sumo amargo del Norte, tierra de nitratos? Contrastes económicos entre la Industria del Norte y la Agricultura del Centro y del Sur, contrastes espirituales y étnicos como el de la Aristocracia y el Pueblo que expresan mundos diversos, contraste entre la historia popular y la historia oficial, hacen que el alma de Chile no pueda captarse inmediatamente. La Sociología chilena debe avanzar por una zona de prejuicios, por un vestíbulo de mitos, porque aquí no se realizó como en otros países de América la simbiosis turbulenta de las revoluciones y guerras civiles. La homogeneidad racial de que alardea cierta conocida imagen de Chile no es nunca homogeneidad espiritual ni homogeneidad política. El sentido de grupo social era aquí más fuerte y aislador que en los países del Atlántico por donde entraron emigrantes rumorosos o que en esos países de pradera o llanura-Venezuela, Argentina-donde el hombre de a caballo fué obstinado pastor de hombres. Excepto Portales que más que caudillo fué organizador, legislador de una clase social, Licurgo o Dracón de la Aristocracia, Chile no ha dado esas individualidades erguidas sobre 
el medio social con insistente y personal decisión de poderío. El grupo social fuerte actúa sobre el hombre elegido en dos formas que expresan toda la técnica de la política chilena hasta 1920. O bien se elige el hombre del grupo cuya personalidad opaca no aflora a la superficie, el verdadero Rey merovingio que en la historia chilena se puede llamar don José Joaquín Pérez o don Ramón Barros Luco, o bien en un momento de peligro se elige dentro de la clase social que no gobierna el hombre de voluntad enérgica comprometido y formado por la clase dominante, que será el brazo ejecutor, el cerebro pensante de los que no actúan. Este segundo tipo de hombre y uno de los mayores, si no el mayor estadista que ha dado Chile, se llamó don Manuel Montt. Todos los manuales de Historia chilena recuerdan esta verdadera educación del poder que la clase aristocrática suministró a Montt, el modesto estudiante de Petorca que va creciendo como un árbol de tronco duro bajo su cuidado vigilante. Montt fué en Chile un Porfirio Díaz sin militarismo; una magnífica cabeza de quirite romano, un hombre que incorporó su patronímico catalán y hasta entonces oscuro, en la heráldica orgullosa de la Aristocracia chilena. Estos hombres-Montt, Portales-fueron los segadores de la maleza democrática; los que dominaron un tiempo tormentoso y lo entregaron ya serenado y manso al cuirlado del tranquilo administrador. Después de ellos continuaba la firme solidaridad del grupo. Por estos dos hombres Chile fué el menos suramericano de los países del Continente; es decir el menos revuelto. No justipreciemos demasiado esta tranquilidad que hizo crisis con la República parlamentaria y plutocrática del siglo XX. El alma colectiva como la tierra chilena aparentemente muy sólida, guardaba escondido ardor.

El disimulo fué la forma chilena casi incomprensible e invalorable para quien está acostumbrado a la 
historia más bárbara, de cargado acento personalista, de mayor dramatismo que puede ser la historia argentina o venezolana. Ni un Rosas, ni un Guzmán Blanco, ni un García Moreno. Montt vuelve de la Presidencia de la República a la Corte Suprema. Fué uno de los creadores de ese estilo jurídico, molde y cuño metálico que Chile aplicó a los hombres que sobresaliendo, desertaban del grupo Junto al Palacio de los Tribunales de Justicia, Montt está con su amigo Varas consultando un Código y sosteniendo la granítica columna de la República Pelucona. Es un orden arcaico que parece demasiado viril, ya anacrónico, a estos hombres más nerviosos de la República liberal, plutocrática.

Pero a esta forma del disimulo, táctica reveladora de la política del grupo, especie de tabú que se conserva aunque ya se rompan las estratas de la antigua Geología social, hay que adentrarse cuando uno quiere entender la política chilena. La tiranía del grupo que toma naturalmente un molde jurídico, impersonal, es siempre más soportable que la voluntad de uno solo. Chile no adornó a sus mandatarios con aquellos florones de adjetivos pomposos, con la liturgia del título que envanecía a los caudillos de la otra América más voluntariosa. Don Manuel Montt no se encargó como Melgarejo y Guzmán Blanco sus uniformes a los modistos militares del Segundo Imperio. Lleva en la estatua una sobria levita de Juez de Provincia. Tampoco por contraste, como el reverso del cuadro, se toleraba en el trato social el tuteo despreocupado de otros países de América. En Venezuela, país llano, pastoril, aventurero, el tuteo es la nivelación oclocrática que ha producido la guerra civil, o en último caso una prenda de garantía, una letra girada sobre el porvenir siempre oscuro, ya que uno no sabe si ese campesino será mañana General. En Chile entre el 
«Patroncito» $y$ el «Roto» existen innumerables estratas.

El hombre de acción para no despertar el recelo del grupo obra, pues, disimuladamente. El vocabulario autóctono chileno es uno de los más ricos del Continente en palabras que expresan el acto de esconderse, de agazaparse. "Apequenarse, hacerse el leso» son expresiones que sólo en Chile tienen sentido. Ellas indican el acto del inteligente que sólo ocultándose o empequeñeciéndose, dandó una vuelta completa al carrousel consigue su propósito; del político que cuando quiere aumentar su repertorio de noticias parece descender de la luna. De esta manera se conquista una confianza oblicua; el individuo se injerta-sin hacer ruido-en el grupo social. En el folkiore chileno ello forma el magnífico anecdotario de don José Joaquín Pérez o de don Ramón Barros Luco. Todo argentino parece exagerado y fanfarrón cuando se le coloca junto a un chileno; el primero es virtualmente el hombre que se adueña de toda la vereda, mientras que el chileno se encoge, se desliza. Lastarria, Vicuña Mackenna fueron dos grandes personajes chilenos que no pudieron ascender a la alta política porque se expresaron demasiado. Cuando un día en el Congreso dijo Lastarria: «Tengo talento y lo luzco», se le admiró la frase, pero había confirmado su sentencia de soledad. En la tragedia de Balmaceda-el más vasto drama político que conozca la historia chilena-actúa esta resistencia del grupo social contra el individuo relevante; desertando de las imposiciones de sü casta Balmaceda quiere hacer una política personal de grandes obras públicas y de grandes apetencias de masas, como Pisístrato. Chile no se parecía a Atenas sino a Esparta, y por ello Balmaceda fué sacrificado. Al gran político lo puede suceder un oficial de Marina que llevaba el apellido Montt, lo que parecía bastante, y otro de los jefes del movimiento revolucionario se 
llama Barros Luco o el sentido común, la falta de nervios, la fría pachorra en correcto traje de caballero. Chile en ese tiempo había operado el tránsito de la Aristocracia a la Plutocracia. El ideal de gobernante ya no es un austero legislador que lleva botas de becerro y amplio pantalón surcado de rodilleras como don Manuel Montt. Es el caballero semi-urbano y semi-rural, especie de gentleman inglés adaptado al paisaje del valle Central. La vida de Club es entonces muy intensa; saber conversar en el Club un malicioso cuento criollo, aplicar a los negocios la misma astucia, los mismos diminutivos con que el huaso del campo esconde sus intenciones, tener un gran fundo con su «stud» y su "haras» de animales seleccionados, lujo acaso demasiado caro, pero que se le muestra a los. amigos en las fiestas del fundo, jugar a la Bolsa grandes fortunas sin abandonar el puro imperturbable que ahuyenta toda mueca, todo rictus que pudiera ser peligroso, son entonces símbolos y formas del poderío. Una fotografía que hemos visto en la Biblioteca $\mathrm{Na}$ cional reproduce una Convención liberal reunida en Santiago allá por el 90 y tantos. Es un documento revelador de toda la estrategia y el estilo político de la época. En la casa de un rico caballero santiaguino amoblada con los altos muebles del estilo Imperio y abundante de las alfombras y los cortinajes de un tiempo que no amaba el aire libre, se han reunido quince o veinte ilustres personas que visten el mismo chaqué negro y los mismos pantalones a cuadros que fabricaban para la Aristocracia, los sastres franceses de Santiago. Ellos encarnan en sus rostros impasibles, en la mesura con que se apoyan sobre sus labrados bastones de contera de plata, el alma cerrada, la "combinación» del grupo. Estos quince o veinte caballeros eran la Política. La decisión que ellos tomaban se trasmitía al país por medio de los compadres, la parentela, los ‘clientes; movía por último en un día co- 
loreado y bullicioso de jinetes, de altos sombreros y rojos ponchos de huasos las masas campesinas electoras. $\mathrm{Y}$ los apellidos, los nombres que sonaban, eran siempre los mismos.

Cuenta don Domingo Amunátegui que cuando las elecciones del año $96 \mathrm{ni}$ Reyes que representaba las fuerzas liberales de la «Alianza» ni Errázuriz que representaba las fuerzas conservadoras que formaron después la "Unión», obtuvieron mayoría en los colegios electorales. Correspondía decidir al Congreso. Pero los partidarios de Reyes advirtieron que en el Congreso predominaban los hermanos, primos y clientes de don Federico Errázuriz Echaurren. Y el problema de si éstos tendrían derecho a voto en una decisión tan importante, llegó a constituir problema público en la prensa y los discursos políticos de aquellos días.

El pueblo, pues, estaba ausente del drama. Portales calmó al pueblo casi rural de su tiempo, fomentando las tolderías y las chinganas. El pueblo para el gran Ministro era un niño bárbaro que apetece comida, trago y diversión. El propio Portales iba a buscar popularidad, a sumergirse en la dionisíaca colectiva zapateando una cueca bajo las ramadas, apurando su vaso de chicha y dirigiendo una frase de escatológica y abultada chilenidad a la mujer que golpea el arpa. La facilidad de la vida en aquel valle central, antes de que llegaran el confort y la industria moderna no hacían desear más a este ingenuo Juan Pueblo en que se juntaban alborozadamente las sangres de Castilla, Andalucía y Arauco. Había como en Esparta, como en toda sociedad aristocrática un verdadero abismo étnico entre la Aristocracia formada en el siglo XVIII por los comerciantes vascos de apellidos de ásperas erres, y el pueblo que mántenía los 
patronímicos sevillanos y extremeños de la conquista. El «roto» era para la Aristocracia la clase pintoresca cuyas exageraciones y dichos hacen sonreír porque parecen las manifestaciones y los signos de una humanidad diferente. Como los aristócratas romanos de la República, antes de las guerras púnicas y de la conquista del Mediterráneo, aquella clase dominante se había construído una Historia, verdadera crónica heráldica en que el derecho a la gloria y la tradición se los reservaban unas cuantas familias. El roto no podía leer tan severa historia y se entretuvo con los cuentos de Pedro Urdemales, con los corridos, con la leyenda de Manuel Rodríguez que fué el héroe que había entendido mejor el alma del pueblo, y con aquellos folletines truculentos, hijos espúreos del folletín francés, donde algunos escritores del pueblo como Ramón Pacheco les contaban historias fantásticas. Y como el folletín había tomado su técnica y su filosofía a las novelas de Eugenio Sué, como el movimiento del iluminado Bilbao había conmovido las capas profundas del alma popular hacia el año 50, el pueblo se hizo anticlerical.

Pero el orden, la cohesionada fuerza de la Aristocracia eran muy vigorosos para que ese movimiento popular de las ciudades tomara la periferia de los campos y engendrase revoluciones. Las primeras sociedades de artesanos, los bellos discursos libertarios del Radicalismo-para un pueblo que como todo pueblo americano ama el gesto y la frase-, la orgía colectiva que producía la chingana, eran bastantes para libertar el alma de este pueblo. El centralismo de un país estrecho, sin "hinterland», sin regiones aisladas, con una ciudad que ya entonces era grande entre las de Sur América y que parecía el centro unico del poder y la riqueza, impedían esos movimientos de masas y la agitación de caudillos regionales como en Argentina, México, Venezuela. 
Con la industria y la plutocracia engendradas por la guerra feliz del salitre, aparecen los primeros mitines. Un sordo rencor irremediable va colmando el alma de este pueblo que es dentro del Estado chileno otra nacionalidad, otro Estado aún sin forma, cuya Historia, cuya Economía, cuya Moral no pueden medirse con la escala que sirve a las clases dominantes. La Geología, el paisaje, la tierra, son ahora como nunca los símbolos e imágenes de la verdadera alma chilena. Se ve el granito, pero abundan también las rocas ígneas. Bajo las sólidas estratas semejantes a las fuertes oligarquías que edificaron la plataforma del país-la ley, el Orden, la Historia escrita-, hay un pueblo inquieto que pugna también por hacer historia $y$ que se agita sin forma ni reposo como un movido fuego central.

Esta vida aparte, sin ilusión ni esperanza, basada sólo en lo material lo condujo a elaborar todo ese complejo de estática fatalidad, de primitivo anhelo mágico que expresa la "Tinca". Las condiciones espirituales del roto: valor, generosidad, patriotismo, espíritu de aventura, no se han aprovechado aún para una construcción nacional. El alma popular ha acumulado desesperanza. Ha seguido a muchos Moisés por el camino del desierto, pero aun no advierte los collados fértiles de la tierra prometida. No es sólo anhelo de vida material; es también apetito de símbolos. Este pueblo puede esperar el maná muchos días-sobre él han llovido las agrias camanchacas del desierto salitrero, la tormenta andina, los vientos del Cabo de Hornos-, pero necesita apretarse en torno del Arca salvadora; saber para qué lucha. Escritores $y$ viajeros han rećogido la odisea ultramarina de esos rotos enérgicos, "pata de perros". Ellos cuentan entre los primeros «pioneers» de la California yanqui donde el año 47 se había descubierto el oro. En el bello libro de Pérez Rosales, poderoso tes- 
timonio de vida y energía popular, ellos son los que construyen las primeras casas, establecen los primeros negocios y hasta reparten las primeras cuchilladas en la agitada y cosmopolita ranchería que era el puerto de San Francisco en aquellos años. Cualquier roto equipaba su tosca lancha maulina, contrataba sus hombres valientes, llenábala de huesillos, de grasa, de cebollas, de trigo e iba con su decisión y sus productos de la tierra, al Pacífico del Norte, después de cincuenta o más días de mar gruesa. Instinto marino más que ciencia naútica. Era una energía popular, libre, de pueblo viril y rebosante, a espaldas de los Gobiernos y los Estados, detenidos como siempre en cuestiones más próximas. La expresión «roto sufrido» marca este estoicismo viril y andariego. Como obrero se adapta con rapidez al mundo de la maquinaria y responde de puro oído en Iquique y Antofagasta, al inglés que le hablan los gringos. Todas estas cualidades vienen contrarrestadas, depreciadas, por la falta de estímulo y previsión personal, por el fatalismo que le oxida. El roto vive al día; los billetes que ganaba en las salitreras los extraía del bolsillo con mano de gran señor, y los arrojaba en desdeñoso puñado sobre el mesón de la cantina. Después seguía su rumbo con el traje destrozado, haciendo de sus andrajos un oriflama de despecho y rebelión. Apartado de todo mundo social ellos constituían la enconada frontera contra el mundo del «chute» o del «pije». Sabe que por más dinero que gane no cambiará su posición; no se conmoverán un centímetro estas capas duras e incomunicables que forman la sociedad de Chile. Aquí los movimientos sociales engendran doctrina, lucha ideológica, pero no alteran el orden preestablecido. Llamarse Sepúlveda o Leiva en Chile, bellos nombres andaluces, gallegos o extremeños que andan en la canción y la picardía popular, constituye un irremediable destino. El aristócrata en esta edad plutocrática 
puede hasta haber perdido su fortuna, pero conserva sus dos erres, la aspereza de su patronímico vasco y ello lo ampara y defiende como un último salvoconducto. El comerciante extranjero, el profesional de clase media enriquecida, el judío, sacrificarán lo mejor de sí mismos en rendido homenaje a la superstición heráldica.

El pueblo soterrado que no hallara como en otros pueblos de América el escape libre de las revoluciones, miró el mundo a través del fatalismo mágico de la «Tinca». No se conoce el alma de la muchedumbre chilena sino penetramos en esta especie de resignación asiática o superstición primitiva-en un pueblo tan viril-, que forma ese complejo. No es la «chance* francesa, ni siquiera el azar español. Es algo más confuso. El hombre duda de todo; las condiciones personales, el estudio, el esfuerzo no sirven para dominar un mundo vago regido por la casualidad y la sorpresa. El hombre que triunfó, sólo tuvo «tinca». Es decir, en un día cualquiera, fué llevado como un perro por su olfato; dijo sin esforzarse la palabra que era necesaria, cuando el llegó todos se volvieron como si lo estuvieran esperando.

La tinca llega o no llega. Entre ella y el sujeto no se establece una relación lógica de capacidad, ni siquiera de rumbo. Es un poco la historia de aquel leñador de Copiapó, Juan Godoy, que saliendo una mañana al campo se encontró con un rico filón de plata. Es la filosofía de un pueblo minero, de aquellos viejos que en las provincias de Atacama y Coquimbo están siempre esperando otra mina de Juan Godoy. $Y$ mientras la tinca cae a nuestros pies, fulgurante como un aereolito, no vale la pena esforzarse. El hombre no tuerce la corriente de las cosas. Y el roto nómade que con sus billetes ganados al calcinado salitre, al trabajo terrible del desrripiador o del barretero, colmó una noche de orgía, de vino y amigos, de 
simple liberación de su alma confusa en Taltal o Tocopilla, los puertos del nitrato, regresaba al Sur en la cubierta de un barco con los bolsillos deshilachados y vacíos. Unos químicos alemanes trabajando en sus laboratorios, habían descubierto el salitre sintético. Están casi paralizadas las faenas del salitre que nutrieron el presupuesto chileno y contribuyeron a formar una clase media de funcionarios, profesionales y técnicos, durante cuarenta años. Otro efecto, otra sorpresa de la «Tinca». Los políticos también se encomendaban a ella como a una divinidad hindú de cinco brazos. Nuestro Juan Roto, hombre imprevisor y sin esperanza, ahora escucha peroraciones comunistas en una plaza del arrabal santiaguino.

Cuando movimientos periódicos, semejantes a esos que los volcanes chilenos mandan a las despreocupadas ciudades del valle Central en detonación persistente, en cálido rocío de cenizas y proyectando sus nubes amenazantes en el claro paisaje de cielos, frutas, praderas de trébol y alfalfa; cuando desde un lejano epicentro-minas de carbón o de cobre-, partía un temblor que conmovía inopinadamente la firme paz de los Ministerios, los políticos asustados y urgidos prepararon leyes sociales. Setenta mil hombres empleados en el salitre, cuarenta mil en el cobre, treinta mil en el carbón; marineros, ferroviarios, obreros fabriles, ya formaban una multitud más hirviente y tumultuosa que aquellos rotos de la chingana y arrebolados huasos para la fiesta del Carmen, sobre los que se ejerciera el dominio de los terratenientes y juristas del siglo pasado. La calle santiaguina suele ser la hornalla que disemina en días de elecciones o huelga, estas multitudes jadeantes que vocean su consigna y siguen religiosamente una enseña roja. Anarquistas 
y comunistas pelean una batalla interminable. Otra vez todo ese vago ensueño de realización se pone en un hombre, un caudillo. Y como si el doctrinarismo no segara en estas multitudes sufridas las fuentes mismas de la alegría, del instinto, de lo irracional, del buen pueblo que son en el fondo, se dan al hombre o al bando enemigo los más maliciosos apodos criollos. El pequeño "palomilla», el "gamin» de las ciudades, el errante lustrabotas es el que pronuncia entonces la imprecación más chilena. Una vez, en 1931, para un mitin de desocupados iban ellos en fila silenciosa con sus mujeres, sus criaturas al brazo y hasta sus perros, cuadro familiar que subsiste hasta en el caors, en la profunda grieta humana abierta por una economía desorganizada. Recordaba ese oscuro desfile de humanidad muda, aplastada bajo el dolor elemental, adherida todavía a la tierra, a sus hembras y sus animales que marcha cabizbaja en el «Enterramiento en Ornans de Courbet.

Si las leyes sociales que a regañadientes o como llamativa bandera eleccionaria les dan los políticos, pueden mejorar el nivel económico de este puebloel presente ensayo puramente poético e intuitivo no alcanzaría a tratar tan ardua cuestión-, creemos que ellas no bastan para la apetencia de vida integral que sufre el pueblo chileno.

En este momento el diagrama de la temperatura, marca una curva depresiva. El problema no es puramente económico, es también espiritual. Chile, el país aislado, de nervios fríos que en el pasado siglo pudo crear un nacionalismo fuerte, ahora está sin rumbo. Germinan sectas extrañas, se pelea por pequeñas cuestiones de doctrina, quedan empantanados los partidos y los grupos en el bache de las abstracciones. Falta a todos la gran idea que transforme no sólo las condiciones de la vida material o el cerebro pensante de los ideólogos, sino que haga brotar en alegría, de- 
cisión, heroísmo, las obturadas fuentes de la vida colectiva. ¿Esta crisis preludia en nuestros inquietos pueblos criollos, un rebrotar, una conciencia nueva y ecuménica como la que en el siglo pasado animó el movimiento de Independencia? Recuerdo con optimismo que en el paisaje chileno donde la estratificación parece más dura y milenaria, saltan y borbotan de pronto, numerosas fuentes termales. Necesitamos de ese plutonismo creador, cálido, vivificante, que lleva escondido la tierra chilena, toda la tierra americana.

El ideal, el impulso no puede proyectarse hacia el pasado. Ya Chile no puede ser aquella aislada Esparta montañosa de guerreros, historiadores y pedagogos que nos devuelve una conocida imagen. No existen en el territorio estrecho esos "hinterland", esos FarWest llenos de promesas donde otros pueblos como Estados Unidos y actualmente Argentina, encuentran la empresa y el adiestramiento de energía nacional. La política chilena toma cada día un más reconocible estilo urbano. De la ciudad hacia el campo, por la línea del longitudinal, irradia todo movimiento. Pero como este esfuerzo de pueblo aislado que debió a la obligada influencia de su soledad instituciones y formas políticas a que todavía no llegaban otras naciones del Continente; como creó un Estado mientras otros países estaban aún en el combate con la Naturaleza y las fuerzas telúricas, acaso pueda surgir aquí, de entre las reflexiones de esta hora de prueba, la gran idea histórica, la única que puede incorporar a nuestros pueblos desunidos a la Economía y la Cultura mundial: la idea ecuménica indoamericana que ya para nosotros no es sueño de visionarios, sino la única posibilidad de vivir.

Pensamos que como en las logias y los ejércitos de hace cien años, nuestra inquieta juventud de América volverá a encontrarse para realizar un plan grandioso. Veremos entonces que lo que nos une es mucho 
mayor que lo que nos separa; que el aislamiento es lo que nos entrega a la voracidad extranjera, y lo que debilita en esta América que habla Español, el sentimiento nacional. Chile como toda nación indoamericana busca esa idea nacional que no puede edificarse sino sobre la común Cultura, la organizada Economía y la vasta voluntad de permanencia histórica.

Al bloque cultural y político latinoamericano con que ya soñamos, para salvarnos, Chile aporta su tradición de pueblo sagaz y tranquilo que conoció el Estado mientras otros vivían en la polvorosa montonera, que tiene ya una industria que aspira a ser libre, pero que sufre como todos de falta de eco, de afonía espiritual.

Ya hay un cansancio contra la política que se consumió en el detalle, en el pequeño beneficio inmediato. La misma violencia y el estacional retorno de las crisis, nos hacen desconfiar de la situación lograda, de la ganancia inmóvil, de la vida estática que defendían tan celosamente nuestros padres. En esta zona enrarecida de Historia Universal que atravesamos, el acontecer fluye y se escapa por entre los cercos que intenta tenderle nuestra previsión. El hambre del mundo es en gran parte, hambre de fe. Y sacarla de sí misma, arrojarla a las siembras del porvenir para crear su ra$z a$, es el deber de Chile como de toda tierra americana.

Puede que después de las generaciones escépticas, desarraigadas y cosmopolizantes que rebajaron y deprimieron nuestro destino criollo, veamos el milagro transfomador de una nueva generación religiosa. La temperatura de fe es la que demanda toda creación trascendente; ella se necesita para fundir las imágenes de una obra de Arte y para juntar en la más complicada obra que es un Estado, en la alegría y la disciplina de una vasta Historia nacional, el grupo humano contradictorio. Los pueblos como los hijos, brotan de las cálidas entrañas. 